\title{
Hume and Frege on identity
}

\author{
John Perry
}

Published online: 11 September 2009

(C) The Author(s) 2009. This article is published with open access at Springerlink.com

One single object conveys the idea of unity, not that of identity.

On the other hand, a multiplicity of objects can never convey this idea, however resembling they may be suppos'd.-David Hume

Identity gives rise to challenging problems-Gottlob Frege

\section{Introduction}

Hume's difficulty with identity is, according to Donald Baxter in his excellent book Hume's Difficulty ${ }^{1}$ :

How can we represent there as being some things that are perhaps numerically identical and perhaps numerically distinct?

I'll call this 'the uncertainty problem'. This difficulty about identity takes a rather special form within Hume's philosophy, but the problem, Baxter says, is real and not specific to Hume, and remains unresolved. And he says, it is quite distinct from Frege's problem about identity.

In the first part of this essay, I will argue that Hume does provide an answer to the problem, so long as we exempt the uncertainty problem from what I will call the "subject matter condition". In the second part, I'll argue that Frege dealt with the same problem, and, as different as the concerns of the two philosophers were, his solution is, in a recognizable sense, Humean.

\footnotetext{
1 Baxter (2008).

J. Perry $(\bowtie)$

Philosophy Department, Stanford University, Building 90, Stanford, CA 94305-2155, USA

e-mail: johnperry43@gmail.com
} 


\section{The problem}

Imagine seeing a plane in the sky, which we'll call A. As you watch it, it disappears behind a cloud, and then, a couple of moments later, emerges on the other side. It is out of sight long enough that it is conceivable, if not likely, that what you saw was one plane going behind a cloud, after which it turned away so that you never saw it again, while another flew into the cloud from afar, and then turned at such an angle as to emerge from the cloud just as the first plane would have, had it continued on the original course.

You might have an uncertainty, as to whether you had seen one plane or two. "Were those planes the same plane?" you might ask yourself.

How should we think of this state of uncertainty? It seems that, for all you know from the evidence of your senses, two quite different situations could obtain. In the first, which I am supposing to be the actual one, a plane enters the cloud from your left and the same plane emerges from the right. In the other, a plane enters the cloud from the left, and a different plane emerges, a moment later, from the right.

But this way of representing the situation seems to leave something out. You are wondering about a specific plane, A. There ought to be something in the way we model your epistemic state that captures that fact. With regard to the first situation, it seems we can specify that the plane involved, the one that enters and leaves the cloud, is A. But what about the second situation? They cannot both be A. Since it was A you saw at the beginning and at the end of the episode, there is no more reason to specify that one or the other is A. We can't use A, the plane you actually saw, to model both possibilities. But both possibilities are possibilities concerning the plane you saw, and we can't very well say that we are modeling your epistemic situation if we leave that fact out.

\section{Hume's solution}

According to Baxter's illuminating analysis, Hume maintains that a steadfast object, although it is not a succession, and by itself affords no idea of time, can neverthless co-exist with each impression in a succession of different impressions, which does provide an idea of time. This gives us what I'll call an original identity structure. An original identity structure involves a single object, A, a pair of distinct objects, B and $\mathrm{C}$, and a relation that holds between each of the distinct objects and the single object. In the basic Humean situation, the kind from which we derive the idea of identity, the single object is a steadfast impression, and the distinct objects are successive fleeting impressions, that co-exist with the steadfast impression. Such successive impressions provide us with our idea of time. So, to borrow Frege's language, in the basic situation we have three modes of presentation of one steadfast object: the steadfast impression itself, and two complex impressions, the steadfast impression as co-existing with the first member of the succession, and the impression of it co-existing with the second member. 
This structure of impressions is that from which we derive the idea of identity. But in the basic situation, the issue of uncertainty about identity won't arise. We know from our impressions that the conditions for identity are met.

The issue of uncertainty arises when we apply our idea of identity to cases in which we don't have a steadfast impression, but two steadfast impressions which resemble one another. In that case, according to Hume, in his metaphysical mood, there really isn't identity. But this is the sort of situation in which we ordinarily apply the word "identity" and take there to be a single object, because we have adopted the fiction of independent objects that persist when we don't have impressions of them, either in the confused way of ordinary folk do, thinking inconsistently of an unperceived impression, or the more sophisticated but ultimately groundless way of philosophers, employing the doctrine of double existence. In either case, our primoridal concept of identity is the key; we mistake a succession of resembling steadfast impressions for a single steadfast impression, and then invent the idea of a persisting object, of one sort or another, to make sense of our mistake. Hume's two candidates for persisting I'll call C-objects and Pobjects. C-objects are, according to Hume, those of the Common man; they are basically impressions that continue to exist when they are not impressions of anyone. P-objects are the Philosophers' objects, conjured up from the doctrine of double existence. They are not impressions, but objects that are in some way responsible for our having impressions.

Let's adopt either the philosophical double-existence view, or the incoherent view of continued independent impressions, so that we can and distinguish between our impressions and the persisting things they are of, and just call fictional identity 'identity'. Does Hume give us an account of identity, so conceived, that solves the problem of uncertainty?

So let's now say that a standard (Humean) identity structure consists of an object, like an airplane, and two perceptions of it at different times, or more generally, an impression of an object of a certain kind, together with a memory of an earlier impression of it.

Standard Humean identity structures do not solve the uncertainty problem. We need to take a further step, to what I'll call a potential identity structure. This is the case where we have two perceptions of an object of a certain type, that are so related that for all we know it is possible that there is a single object perceived at both times, and also possible for all we know that there is not. The uncertainty would be represented, in more or less Hume's framework, by a pair of ideas, corresponding to the what the unperceived parts of the world are like if there is a single object both perceptions are of, and what the world would be like if there were not.

Suppose we are uncertain whether the fire in the grate is the same fire we saw earlier. The earlier and later impressions of fires will be supplemented with two ideas, to provide a potential identity structure. One idea will be drawn from the cases in which we have observed a single object with no interruption, as when we stay in the room and watch the fire burn down. The other idea will be drawn from cases in which we remained in the room and saw one fire extinguished, and replaced by another smaller fire, which, after a bit, looked just like the first fire would have, had it been allowed to burn down. Of course, Hume needn't suppose these ideas are 
actually based on impressions, since once our cognitive system gets going, our imagination can construct such ideas from materials provided by other impressions.

Or consider the airplane case. Suppose on some cloudless days you did a lot of airplane observing and, by copying, assembled an inventory of ideas. You had the more or less steadfast impression of a single plane flying a considerable distance through the sky, an impression that overlapped with other successive impressions. From this experience you added a complex idea, call it $I$, to your inventory. You have also had impressions of one plane flying a certain distance and then turning away, while another plane appears from the distance and turns into roughly the path of the first plane. Call this complex idea $I^{\prime}$. You watch A, flying into the cloud: impression $p$. A bit later you see A emerging from the cloud: impression $p^{\prime}$. Your uncertainty structure consists the impressions $p$ and $p^{\prime}$, together with the ideas $I$ and $I^{\prime}$.

What about the specificity problem? What makes this structure a representation of the possibilities concerning A, since A itself is not a part of the structure?

When Hume is thinking metaphysically, about our original idea of identity, he can directly characterize our minds by the objects we are thinking of. The thing that is identical is the steadfast impression, and the steadfast impression is in our mind, with no hidden parts or aspects. I don't see how he could represent uncertainty about identity with these materials, but it doesn't seem that he needs to, since in this primordial situation there will be none. But one we are thinking of C-objects or Pobjects, it seems Hume needs to revert to characterization of that is not directly in terms of the objects we are thinking of, but rather in terms of perceptionsimpressions and ideas-that are of those objects.

That is, once we are in the realm of C-object or P-objects, Hume offers us a role based theory of cognition: we think about objects as the occupants of certain roles in our lives, roles that become complex and nested. You first think of A as the plane your perception $p$ is of; that is, you have the perception $p$ associated with the idea of an airplane, and the expectations with which this idea is associated. Then you remember $\mathrm{A}$; your memory is of the perception $p$; and $p$ was of A. While a steadfast impression may be directly involved in your cognition, a C-object or a P-object will not be. It will figure into your cognition only by playing a certain more or less complex role, relative to the impressions and ideas, that figure directly into your cognition.

So your mind contains, let's say, a present impression of a plane, a memory of a recent impression of a plane, and two ideas corresponding to what might have happened in the cloud. The particular plane you saw, both times, is A. How does what goes on in your mind relate specifically to A? Simply that A is, in fact, the plane your perceptions were of. It is the plane you saw, and are thinking about, because it is the plane that fills the roles that characterize your mind.

\section{Austin's example}

Let's look at another example, based on David Austin's "two tubes" case. ${ }^{2}$ You are part of an experiment. You are looking through two tubes, one for each eye. Each

\footnotetext{
2 Austin (1990).
} 
tube is pointed towards a blue circle on a piece of paper. You can't tell if the two tubes are pointed at the same circle, or two circles that are exactly similar. You name the circle(s), for the purposes of thought and deliberation, assigning $\alpha$ to the circle you see with your left eye, and $\beta$ to the one you see with your right eye. You think to yourself, "For all I know, $\alpha$ is $\beta$, but also, for all I know, $\alpha$ is not $\beta$.

Here we don't have the element of time that was so important to Hume, in his analysis of our idea of independent, persisting objects. Still, his idea seems capable of generalization to handle this sort of situation. We have two perceptions, and the question is whether there is a single circle both perceptions are of, or two different circles. You have two perceptions. You have two ideas, of how the situation you are in might look from a perspective you don't have. One idea is of the two tubes being directed at a single circle, the other of the two tubes directed at different circles. The two perceptions plus the two ideas provide a potential identity structure.

\section{Referentialism and the subject matter condition}

Austin presents his two tubes problem as a problem as a problem for the theory of demonstratives and proper names that holds that they are referential. To say that they are referential is to say that they contribute the objects they designate, rather than identifying conditions for those objects, to the propositional contents of the statements in which they occur-a doctrine familiar from the work of Donnellan and Kripke on names, and Kaplan on demonstratives. ${ }^{3}$ Suppose that in fact there is but a single circle you see through both tubes, so that in fact $\alpha$ is $\beta$. Then when you say, or think, " $\alpha$ is $\beta$ ", the names, $\alpha$ and $\beta$ both contribute the same thing, that circle, to the propositional content of your utterance or thought, and it will turn out to have the same propositional content as your utterance or thought of " $\alpha$ is $\alpha$ " or " $\beta$ is $\beta$ ". But, intuitively, you know that $\alpha$ is $\alpha$, while you don't know that $\alpha$ is $\beta$. Unless we deny our intutions, something has to give. It seems to me Austin is right about this.

But what should give? Let us say that the objects your utterance refers to, or the objects your belief is about, are their subject matter. These are the objects whose properties will determine the truth or falsity of your utterances or thoughts. If we think that the content of a thought is its truth-conditions, then it seems like the content should consist of the conditions the truth of the thought or utterance puts on its subject matter. Call this the subject matter condition on the representation of thought-content.

What Austin's example shows is that we must give up the subject matter condition. There is clearly a cognitive difference between having two impressions or ideas that are in fact of the same object, and having two impressions or ideas that one takes to be of the same object. Austin shows that we cannot represent the difference, if we adhere to the subject matter condition.

But anyone who adopts a role based picture of how cognitions are connected to their objects will not be attracted to the subject matter condition. Consider your original impression of A. Perhaps you saw that A had a United Airlines logo on its tail. You had a thought, call it $t$,that you might have expressed with "That airplane is owned by United Airlines." Given the role-based nature of cognition, there will be two levels of

\footnotetext{
${ }^{3}$ Donnellan (1970), Kripke (1980), Kaplan (1989).
} 
at which we can analyze the truth-conditions of your thought, depending on whether we fix the occupant of the role, or merely the impression that defines the role:

(1) $t$ is true iff there is an $x$, such that $x$ is an airplane, $p$ is an impression of $x$, and $x$ is owned by United Airlines.

(2) Given that $p$ is of A, your thought is true iff $\mathrm{A}$ is owned by United Airlines.

(1) gives the truth conditions of $t$ as condition on the perception $p$; (2) gives the truth conditions of $t$ as conditions on the subject matter, the airplane A. The two truth-conditions are perfectly consistent; the difference just lies in what we are taking as given, and what we are thinking of as at issue.

Now let $t$ be an identity thought, which you express with,

(3) That plane is this plane

where the your intent is to refer to the plane of which $p$ was an impression with "that plane," and the plane of which $p^{\prime}$ is an impression with "this plane". There are a number of truth conditions we can assign to your thought:

(4) $t$ is true iff there is an $x$ and there is a $y$ such that $p$ is of $x$ and $p^{\prime}$ is of $y$ and $x=y$.

(5) Given that $p$ is of $\mathrm{A}, t$ is true iff there is a $y$ such that $p^{\prime}$ is of $y$ and $y=\mathrm{A}$.

(6) Given that $p$ is of $\mathrm{A}$, and $p^{\prime}$ is of $\mathrm{A}, t$ is true iff $\mathrm{A}=\mathrm{A}$.

(6) analyzes the truth conditions of the thought in terms of A, the plane that was actually perceived. For most purposes, this is a rather pointless level of analysis.

What referentialism shows is that for in all sorts of situations, we are interested in the subject-matter truth-conditions of thoughts. This is because our focus is often on the objects the thoughts are about, and what the fact that people have certain beliefs about them shows about those objects. When we ask, counterfactually, "what would the world have been like, if that thought or statement were true," we are often interested in how the subject matter would have had to be different, not in how the situation of the thinker or speaker would have had to be different.

But when identity is involved, or when the objects don't exist, or when our interest is tracing the pattern of cognitions and not learning about the objects, subject-matter truth conditions may be unhelpful, or not even be available. Referentialism does not show that no other level of analysis of the truth-conditions of thoughts is available. ${ }^{4}$

Baxter is assuming the subject matter condition; that is, he is assuming that part of the difficulty Hume was faced with, was giving an account of how we represent uncertainty about identity solely in terms of the subject matter of the thoughts involved. He says, for example:

Suppose someone is unsure whether Mark Twain is Samuel Clemens. She says, [(7)] ...For all know Twain and Clemens are identical and for all I know they are distinct...

Regardless of what makes this sentence true,... (p. 87)

\footnotetext{
${ }^{4}$ See Perry (2001).
} 
Before letting Baxter complete his thought, let's ask: what does make the sentence true? Assuming the person is sincere, it seems clear that one person, Samuel Clemens, is playing two roles in her life. He is, on the one hand, the referent of uses she has seen and heard and made of the name "Mark Twain," and on the other the referent of uses she has seen and heard and made of the name "Samuel Clemens". The two situations she imagines might be the case are ones in which one person plays both roles (the actual situation) and in which there are two people-one in which, perhaps, Twain wrote sequels to Clemens books, the way that someone wrote a sequel to Margaret Mitchell's Gone With the Wind years after she died.

But, Baxter says,

Regardless of what makes this sentence true, she has represented there as being the same Twain and the same Clemens in different epistemically possible situations such that they are identical in one and not in the other..."

I don't think this is correct. She hasn't said anything about epistemically possible situations. She has said, regarding Mark Twain and Samuel Clemens, that she doesn't know whether or not they are the same. Epistemically possible situations are something philosophers bring in, to analyze what is going on. They are something we use, in representing the truth-conditions of her mental state, not something she says anything about. The question is, in building up these situations, should limit ourselves to subject matter possibilities? Or should we allow ourselves role-based possibilities?

If we limit ourselves to subject-matter possibilities, then we will have the problem Baxter identifies. We will be stuck with the useless level of truthconditions for her thought, and will not be able to make sense of it. There is only one fellow, Samuel Clemens, aka Mark Twain, with which we can build the situations, and try as we might, we can't find a possible situation in which he is not himself. If we allow ourselves roles, however, then we have two roles, and no problem; there are possible situations in which the roles are occupied by the same person, and the actual world, in which Clemens occupies both of them, is one of these. But there are also possible situations in which two people each occupy one of the roles and not the other; the actual situation is not one of these.

To say that we should characterize the mental states in this way, is not to say that our subject is really thinking about roles, rather than their occupants. She is thinking about Clemens, in two different ways, without being sure that that is what she is doing.

Baxter is right, I think, that no one has solved the problem of accounting for the truth conditions of a sentence like (7), while adhering to the subject matter condition, but I don't see any reason anyone should, and especially not Hume, since his account of cognition, at least of C-objects and P-objects, is thoroughly role-based.

\section{Hume and Frege}

So, I claim that Humean potential identity structures are a very promising account of our idea of identity. But what about Frege? Was he concerned with the same problem? Or, more cautiously, is there a problem, with which both were concerned? 
Frege opens "Uber Sinn und Bedeutung" by asking if identity is a relation between names or objects, and giving as an illustration of the difficulty with which he is concerned, the difference in significance between the trivial " $a=a$ " and the informative " $a=b$ ". Although one can scarcely accuse Frege of unclarity, quite attentive students who have worked through the essay a time or two are often unable to say what his final answer is to his opening question. By the end of the essay, we are told that, assuming $a=b$, the two sentences have the same Bedeutung, the truth value True, but but express different propositions (Gedanken), due to the difference in sinn between $a$ and $b$. So we have two propositions, and one truth-value. Neither the names nor the objects have a place in either the propositions or the truth value. So what is his answer?

I think his answer is clearly that identity is a relation between objects, or rather between each object and itself. This relation is the Bedeutung of the concept word '=', and the relation that must hold between the Bedeutungen of the names that flank the identity signs for the Bedeutung of the whole sentence to be the True. The relation that must hold between the Sinne of the flanking signs is determining the same Bedeutung; that is not a relation between the named objects, but it is also not identity.

The important point is that Frege, like Hume, didn't try to get at what was going on in the case of informative judgements of identity in terms of a structure involving only the objects and the relation of identity. A larger structure was needed, involving Sinne and the relation of co-determination as well. Just as Hume saw the need for two different perceptions, Frege saw the need for two different Sinne, and the relation of co-determination between them, to account for the informativeness of identity.

Frege was in the business of logic and semantics, not characterizing mental states. But, as he notes in "The Gedanke," Sinne serve to characterize those mental states that are apprehensions of them. We can characterize the differences in the thoughts (in the ordinary sense) corresponding to $a=a$ and $a=b$ by the fact that they involving apprehensions of different Sinne, and this will serve to illuminate how the different thoughts motivate different actions. So Frege, like Hume, gives us two different roles involved in an identity thought: being the object that the Sinn of $a$ is of, and being the object that the Sinn of $b$ is of.

It is hard for me to see that Frege wasn't worried about the uncertainty problem. He was worried about what we learn from $a=b$ that we don't learn from $a=a$, and thought that what he had to say would deal with problems like the fact that it is the same sun that sets one day and rises the next. Like Hume, he thought that we couldn't get at what one doesn't know, when one doesn't know that $a=b$, just in terms of the relation of identity and the object(s) $a$ and $b$. That is, we can't stick with the subject matter condition. Hume and Frege each find three things involved in a true and informative identity judgement. For Hume, we have one object and two perceptions of it (normally at different times); the perceptions are not identical, but give us two modes of presentation of one object. For Frege, we have one object and

\footnotetext{
5 See Frege (1892, 1918).
} 
two apprehensions of two Sinne; the Sinne are not identical, but determine the same object, if the thought is true.

Baxter says that Hume is concerned with intentional objects, while Frege is concerned with intended objects.

A philosopher might offer us a theory of intentional objects in two ways. He may, like Meinong ${ }^{6}$, Mally $^{7}$, or Zalta ${ }^{8}$, provide us with objects that don't exist, but are nevertheless real and belong in our ontology, and are used to characterize the contents of thoughts. Or, like Russell in "On Denoting," ${ }^{9}$ he might show us how to deal with expressions in the expression of thoughts that appear to designate such objects, without actually adding them to our ontology, relying only on an ontology of more ordinary objects.

It seems to me that Frege and Hume are both philosophers of the second sort, although of course they differ rather dramatically in what belongs in our ontology of ordinary objects.

Frege's Sinne are real objects, part of the third realm. Apprehensions of them are real mental events, that we characterize with the Sinne. Sinne are used in thinking, but they are not what we are thinking about (setting aside cases in which we are thinking about thoughts themselves). When I imagine a large unicorn, there is not a subsisting, non-existent unicorn I am thinking about. Nor am I imagining something about the Sinne of 'unicorn,' a real object. Rather, I am grasping the sinn of 'unicorn' to have thoughts of a certain kind. No unicorns are involved, real or subsistent.

For Hume, when I imagine a unicorn I am employing a complex idea whose parts can be traced back to real impressions. No unicorn, or unicorn impression, is involved.

Hume's structures and Frege's structures bring roles directly into the characterization of identity thoughts. The objects thought about only indirectly, as the real objects that play those roles. In the case of imaginary objects, no real objects play the roles, but the roles still characterize the thoughts.

Suppose I think that there is a unicorn which visits my yard each night, and a unicorn that visits my neighbor Dick's yard each night. On Frege's theory, there are two sinne-based roles: being the Bedeutung of the sinn: the unicorn that visits Dick's yard, and being the bedeutung of the sinn: the unicorn that visits my yard. The structure of my thought assures us that there are two roles, but leaves open whether or not, for what I think to be true, there has to be one occupant of both roles.

Now suppose I go on to wonder whether or not they are the same unicorn. This does not involve the two Sinne-roles being the same or not being the same, but rather involves them having or not having the same occupant.

Hume, I suppose, would look on this situation in the following way. My thought involves two complex ideas, being a unicorn in my yard, and being a unicorn in

\footnotetext{
${ }^{6}$ Meinong (1904).

${ }^{7}$ Mally (1912).

${ }^{8}$ Zalta $(1983,1988)$.

${ }^{9}$ Russell (1905).
} 
Dick's yard. The relevant potential identity structure involves these two complex ideas, and the relation, between ideas, of being copies impressions of the same unicorn. To be true, there would have to be a single unicorn, that fits both ideas. What the world would have to be like to make this true would depend on whether we were thinking strictly, common-sensically, or philosophically.

Baxter connects the distinction between intended and intensional objects to differences of scope. Consider:

(1) Fred wonders whether $A=B$

(2) $\exists x \exists y[x=A \& y=B \&$ (Fred wonders whether $A=B)]$

It seems to me that both Hume and Frege have the materials to provide an account of both (1) and (2), although neither explicitly considers things like (2). (1) is the intentional case, which we have already considered. ' $A$ ' and ' $B$ ' must provide us with roles that fit into the relevant conception of an identity structure.

(2) could be used to symbolize our airplane case. The extra requirements imposed by the quantifiers and identity clauses before the parentheses, require that there be (appropriately) real objects that fit the roles provided by ' $A$ ' and ' $\mathrm{B}$ '; it leaves open whether there is one object that satisfies both roles, or two. ${ }^{10}$

\section{Conclusion}

Thus, in spite of learning from Baxter a great deal about Hume on identity that had been a mystery to me, in spite of repeated engagements with Hume's text, I am inclined to disagree with him on two points, and hold that (i) insofar as we don't burden the uncertainty problem will the subject matter condition, which there is no reason to do, Hume provides a plausible solution; (ii) in spite of their quite different philosophical approaches and interests, there is a problem Hume and Frege are both interested in, and Frege, like Hume rejects the subject matter condition, and finds the multiplicity involved in identity in the objects that directly characterize the mind (perceptions for Hume, the Sinne we apprehend for Frege), and the unity involved in a true identity thought, in there being a single object that the directly characterizing objects are $o f$.

Open Access This article is distributed under the terms of the Creative Commons Attribution Noncommercial License which permits any noncommercial use, distribution, and reproduction in any medium, provided the original author(s) and source are credited.

\section{References}

Austin, D. F. (1990). What's the meaning of 'this'? Ithaca: Cornell University Press.

Baxter, D. L. M. (2008). Humes difficulty. New York: Routledge.

Donnellan, K. (1970). Proper names and identifying descriptions. Synthese, 21, 335-358.

$\overline{10}$ For the issue of quantifying in, in the setting of a Fregean theory, see Kaplan (1969). 
Frege, G. (1892). Über Sinn und Bedeutung. Zeitschrift für Philosophische Kritik, NF 100 (pp. 25-30). [On sense and reference. In Translations from the philosophical writings of Gottlob Frege. (P. Geach \& M. Black, Eds. and Trans., 1960). Oxford: Basil Blackwell].

Frege, G. (1918). Der Gedanke. Eine logische Untersuchung, Beiträge zur Philosophie des deutschen Idealismus I, 58-77 (A. M. \& M. Quinton, Trans., 1956), as The thought. Mind, 65, 289-311.

Kaplan, D. (1969). Quantifying in. In D. Davidson \& J. Hintikka (Ed.), Words and objections (pp. 206242). Dordrecht: Reidel Publishing Company.

Kaplan, D. (1989). Demonstratives. In J. Almog, J. Perry, \& H. Wettstein (Eds.), Themes from Kaplan (pp. 481-563). New York: Oxford University Press.

Kripke, S. (1980). Naming and necessity. Cambridge, MA: Harvard University Press.

Mally, E. (1912). Gegenstandstheoretische Grundlagen der Logik und Logistik, supplement to Zeitschrift für Philosophie und philosophische Kritik, 148.

Meinong, A. (1904). Über Gegenstandstheorie. In A. Meinong (Ed.), Untersuchungen zur Gegenstandstheorie und Psychologie. Leipzig: Barth.

Perry, J. (2001). Reference and reflexivity. Stanford: CSLI Publications.

Russell, B. (1905). On denoting. Mind. 14, new series: 479-493.

Zalta, E. (1983). Abstract objects: An introduction to axiomatic metaphysics. Dordrecht: D. Reidel.

Zalta, E. (1988). Intensional logic and the metaphysics of intentionality. Cambridge, MA: The MIT Press/ Bradford Books. 